\title{
STANDAR OPERASIONAL PROSEDUR ROOM SERVICE NATYA HOTEL, TANAH LOT, BALI
}

\author{
Rimalinda Lukitasari \\ Email: rimalinda.lukitasari@pib.ac.id \\ POLITEKNIK INTERNASIONAL BALI
}

\begin{abstract}
ABSTRAK
Kunci keberhasilan suatu hotel adalah pelaksanaan Standar Operasional Prosedur (SOP) yang sesuai dengan standar yang telah ditentukan oleh masing-masing hotel, sehingga pengunjung merasa puas, nyaman dan mau kembali mengunjungi suatu hotel. Room service di Natya Hotel, Tanah Lot memiliki SOP yang telah ditetapkan, tetapi ada beberapa kendala dalam pelaksanaan SOP. Penelitian ini bertujuan untuk mengkaji mengenai Room service department di Natya Hotel yaitu kendala yang dihadapi dalam pelaksanaan dan upaya Natya Hotel dalam meningkatkan profesionalisme room service man. Penelitian ini merupakan penelitian kualitatif. Teknik pengumpulan data dilakukan melalui teknik obeservasi, wawancara, dokumentasi dan juga studi pustaka. Hasil penelitian mengungkapkan SOP yang dijalankan di Natya Hotel pada departement room service yaitu menerima oderan dari telepon, membuat captain order, mempersiapkan peralatan, pesanan diantar ke kamar tamu. Adapun kendala yang dihadapi dalam pelaksanaan SOP yaitu terkait dengan jumlah karyawan yang sedikit dan kendala bahasa.
\end{abstract}

Kata Kunci: Standar Operasional Prosedur, Room service, hotel

\section{ABSTRACT}

The key of success in terms of hotel industry is the implementation of the Standard Operating Procedure (SOP) determined by each hotel. This efforts important for the guests, so that visitors feel satisfied, comfortable and have willingness to return to visit a hotel. Room service at Natya Hotel, Tanah Lot has have implemented their SOP, but there are several obstacles when implementing it. This study aims to examine the constraints faced in the implementation of Room service department task in Natya Hotel, in order to see the professionalism of room service man. This research used a qualitative research. Data collection techniques are carried out through observation techniques, interviews, documentation and also literature studies. The results of the study revealed the SOP that was run at Natya Hotel in the room service department are receiving orders from the telephone, making captain orders, preparing equipment, orders being delivered to guest rooms. The obstacles faced in implementing the SOP are namely less amount of staffs and language barrier.

Keywords: Standard Operating Procedure, Room service, hotel 


\section{PENDAHULUAN}

Pada tahun 2017 terlihat adanya peningkatan yang signifikan pada bisnis perhotelan. Semakin berkembangnya dunia kepariwisataan dan prospek berinvestasi di Pulau Bali merupakan salah satu penyebab terjadinya peningkatan yang signifikan. Berdasarkan Badan Pusat Statistik Total kunjungan wisatawan mancanegara ke Bali meningkat 779.802 orang atau $15,62 \%$ dibanding tahun 2016 yang tercatat 4,92 juta orang. Dari sepuluh negara yang terbanyak memasok turis ke Bali, hanya dua negara yang mengalami penurunan yakni Australia sebesar 4,21\% dan Malaysia 5,15\%. Sedangkan delapan negara lainnya meliputi China meningkat 39,88\%, India 45,59\%, Inggris 10,07\%, Amerika Serikat $12,11 \%$, Perancis $7,61 \%$, Jerman $15,11 \%$ dan Korea Selatan $15,45 \%$.

Semakin bertambahnya wisatawan dan para pelaku bisnis bidang pariwisata lokal maupun mancanegara, Menyebabkan semakin tingginya tingkat permintaan konsumen terhadap akomodasi wisata. Dengan peluang yang sangat besar, banyak investor yang mengambil kesempatan untuk mendirikan hotel-hotel baru sebagai fasilitas atas tingginya permintaan terhadap akomodasi wisata. Disisi lain juga berakibat semakin ketatnya persaingan dalam saling mengunggulkan kelebihan masing-masing.

Kunci keberhasilan suatu hotel adalah pelaksanaan Standar Operasional Prosedur (SOP) yang sesuai dengan standar yang telah ditentukan oleh masing-masing hotel, sehingga pengunjung merasa puas, nyaman dan mau kembali mengunjungi suatu hotel. SOP merupakan sebuah aturan khusus, prinsip, atau tindakan yang ditetapkan sebagai acuan untuk karyawan dalam menjalankan tugas secara konsisten (Kotschevar \& Luciani, 2007: 188). Disamping pentingnya SOP, peranan sumber daya manusia dalam hal ini juga sangat penting karena sumber 
daya adalah orang-orang yang menjalankan SOP di setiap hotel. Sumber daya manusia tersebut meliputi para Room Attendant, Linen Attendant, Supervisor, Executive Housekeeper, dan bagian lain yang terkait dalam lingkup organisasi hotel (Yasin, 2012). Adanya SOP yang berstandarisasi masih belum bias dikatakan sebuah hotel itu sempurna. Hal ini dikarenakan pelaksanaan SOP seringkali ditemukan kesenjangan yang menyebabkan hasil yang didapatkan kurang memuaskan dari target yang telah ditetapkan. Kesenjangan ini dapat disebabkan oleh berbagai macam penyebab.

Natya Hotel, Tanah Lot, terletak di dekat Pura Tanah Lot yang merupakan Pura yang megah dan paling ikonik di Bali. Di Natya Hotel pengunjung dapat melihat pemandangan alam yang menarik berupa panorama matahari terbenam, hamparan sawah bertingkat kehijauan, dilatar belakangi siluet pegunungan Bali. Guna mempertahankan kepuasan dan loyalitas pengunjung yang menginap, Natya Hotel, Tanah Lot telah menetapkan dan menjalankan SOP hotel yang baik. Hal ini merupakan alasan mengapa Natya Hotel, Tanah Lot masih tetap bertahan ditengah banyaknya pembangunan akomodasi wisata baru di Bali hingga saat ini.

Masing-masing hotel baik itu hotel besar maupun hotel kecil biasanya terdapat restoran dan bar di tempat itu untuk para tamu dapat menikmati makanan dan minuman yang tersedia. Selain itu juga, beberapa tamu yang ingin menikmati makanan dan minuman di kamarnya sendiri. Salah satu fasilitas pelayanan terhadap tamu yang tersedia di Natya Hotel adalah room service. Room service adalah pelayanan makanan dan minuman di dalam kamar hotel. Room service juga dapat disebut in-room dining. Fungsi dari room service sebenarnya sejalan dengan restoran dan bar. Restoran dan bar menjual makanan dan minuman di ruang saji restoran atau ruang saji bar, sedangkan room 
service memiliki kekhususan pelayanan yaitu menyajikan makanan atau minuman di kamar, hal ini juga termasuk menyiapkan pesanan, mengantar pesanan (taking order), menyajikan pesanan di kamar dan mengembalikan peralatan yang telah digunakan dari kamar (check floor).

Room service departement merupakan salah satu pemasukan bagi Natya hotel, karena biasanya room service beroperasi selama 24 jam untuk menyiapkan makanan dan minuman seperti lunch, dinner, breakfast, dan supper (makan tengah malam). Selain itu tugas dari room sercvice waiters yaitu menyiapkan segala peralatan dan keperluan dalam menyajikan/menyiapkan makanan dan minuman serta menyiapkan tray (nampan) dan trolley.

Berdasarkan wawancara yang bersumber pada pengunjung di Nayta Hotel, Tanha Lot, ditemukan beberapa permasalahan yang terjadi pada departemen room service, yaitu dalam menangani pesanan tamu (order) ke room service. Beberapa masalah ini, menyebabkan timbulnya pertanyaan karena Natya Hotel, Tanah Lot pada dasarnya sudah memiliki SOP, tetapi masih terdapat tamu yang kurang puas terhadap pelayanan yang diberikan. Maka, dalam penelitian ini dilakukan analisis penerapan SOP Room Service Natya Hotel, Tanah Lot untuk mengetahui dengan jelas penyebab dan bagaimana cara mengatasinya.

Berdasarkan latar belakang yang telah diuraikan, maka yang menjadi permasalahan dalam penelitian ini, adalah: 1) Apakah kendala yang dihadapi dalam pelaksanaan SOP Room service Natya Hotel, Tanah Lot? 2) Bagaimana upaya peningkatan profesionalisme room service man Natya Hotel, Tanah Lot?

\section{KOSEP DAN TEORI}

Pada bagian ini akan dipaparkan mengenai konsep dan teori yang digunakan dalam penelitian ini. 


\subsection{PENGERTIAN STANDARD OPERATIONAL PROCEDURE (SOP)}

Hampir seluruh hotel sangat menyadari arti pentingnya sebuah SOP. Secara umum fungsi SOP bukan hanya sebagai alat kontrol tetapi juga sebagai alat untuk menjaga konsistensi dari kualitas output dari hotel tersebut. SOP harus dapat didisain bukan sebagai penghambat jalannya operasional suatu hotel. SOP dilihat secara komprehensif. SOP merupakan salah satu bagian dari kegiatan administrasi khususnya mendalami prosedur, sistem dan kegiatan pendokumentasian dalam administrasi suatu hotel. Agar memahami kegiatan dalam suatu pekerjaan dengan baik setiap organisasi atau usaha harus memiliki suatu acuan, instruksi ataupun prosedur kerja. Karena dengan adanya prosedur atau acuan ini para karyawan, atasan, manajemen maupun masyarakat mendapatkan suatu kejelasan serta kemudahan transparansi dalam setiap prosedur pelayanan yang diberikan.

Ada beberapa istilah acuan dalam pekerjaan, antara lain Work Instruction (Instruksi Kerja) dan Standard Operational Procedure (SOP). Kedua istilah tersebut memiliki fungsi dan makna yang sama yaitu sebagai acuan kerja perbedaannya hanya dari pemakaian istilah atau bahasa dalam tiap-tiap organisasi atau usaha.

Adapun beberapa pengertian mengenai SOP menurut Ariefraf (2008) yaitu:

1) SOP adalah satu set instruksi tertulis yang merupakan dokumen suatu aktivitas yang selalu berulang atau rutin.

2) SOP menguraikan kedua unsur operasional administratif dan teknis dari suatu organisasi yang biasanya diatur oleh Quality Assurance.

3) SOP harus diorganisir untuk bisa dipastikan mudah dan efisiens dalam penggunaan dan dikembangkan sesuai dengan kekhasan organisasi. 
4) Tidak ada format SOP yang sangat pas dengan organisasi, pengaturan secara internal akan berbeda menurut masing-masing organisasi dan dengan jenis SOP yang akan dikembangkan.

5) Proses dan prosedur, suatu proses dapat terdiri dari satu atau lebih prosedur. Dalam kasus yang sederhana suatu proses mungkin terdiri dari hanya satu prosedur.

\subsection{ROOM SERVICE}

Dunia food and beverage service adalah dunia yang terkait dengan penyajian atau pelayanan makanan dan minuman dan secara umum erat kaitannya dengan restoran dan bar. Jika dilihat dari sudut pandang hotel, maka food and beverage service merupakan bagian terpenting dari operasional suatu hotel. Departemen Food and Beverage yaitu salah satu departemen yang ada di hotel dan khusus menaungi dan bertanggung jawab atas segala yang terkait dengan food and beverage product ataupun service yang tentunya ada di hotel tersebut. Departemen Food and Beverage memiliki outlet-outlet. Adapun outlet tersebut salah satunya adalah Room Service yang akan dibahas dalam penelitian ini.

Room Service menurut Marsum (2005) adalah salah satu bagian dari food and beverage department yang bertugas melayani para tamu yang menghendaki makan dan minum di dalam kamarnya. Mengingat telepon yang dipergunakan untuk menerima pesanan para tamu dari kamar jumlahnya terbatas, juga karena kebanyakan tamu waktu makan pagi biasanya tergesa-gesa dan kemudian menghendaki makan di dalam kamar saja, maka khusus biasanya room service khusus untuk melayani makan pagi. Pelayanan pesanan makanan dan minuman dapat dilakukan dengan dua metode yaitu menelepon langsung ke bagiam room service atau dengan mengisi door knob menu. Menu ini digantungkan pada tombol pintu kamar sebelah luar setelah di isi oleh tamu. Sedangkan 
menurut Wiwoho (2008), setiap hotel yang berukuran standar dipastikan memiliki salah satu fasilitas yang diberikan kepada tamu, yakni tamu dapat menikmati makanan untuk disantap dan menginap melalui room service.

Menurut Suarthana (2006), Room Service adalah restoran yang dibuka untuk breakfast, lunch, dinner dimana makanan tamu dapat dihidangkan di dalam kamar tamu yang menampilkan menu sederhana dan cepat dengan harga yang relatif murah. Menurut Wiwoho (2008) cara room service menerima pesanan tamu adalah: 1) Menerima telepon dari tamu, menjawab dengan ramah, ucapkan selamat pagi, siang, atau malam. Dengarkan pesanan tamu dengan baik dan hati-hati, 2) Mencatat pesanan tamu pada buku pesanan dalam 3 rangkap data: nomor kamar, jumlah tamu, nama tamu, pesanan catatan berurutan, jam berapa harus diantar, 3) Mengulang pesanan tamu termasuk: nomor kamar, jam berapa harus diantar, 4) Mengucapkan terimakasih setelah tamu meletakkan telepon, berikan slip order lembar pertama dan kedua kepada room service waiter. Baca dan cek ulang kembali pesanan sebelum dikirim ke dapur dan bar, 5) Mempersiapkan peralatan yang diperlukan, 6) Mengirimkan makanan dan minuman ke kamar tamu termasuk bon penagihan atau guest bill langsung ke kamar tamu, seseuai dengan pesanannya.

Pengertian dari room service itu berbeda-beda, tetapi arti dan intinya sama. Room service adalah salah satu bagian dari Food \& Beverage department yang bertugas melayani para tamu yang menghendaki makan dan minum di dalam kamarnya

\subsection{HOTEL}

Ada dua pendapat tentang pengertian hotel. Agusnawar (2002: 13) menyebutkan Hotel sebagai salah satu jenis akomodasi yang menggunakan sebagian atau seluruh bangunan untuk menyediakan jasa 
pelayanan penginapan, makan dan minum, serta jasa lainnya bagi umum yang dikelola secara komersil, serta memenuhi ketentuan persyaratan yang ditetapkan di dalam keputusan Menteri Pariwisata, Pos dan Telekomunikasi. Berdasarkan SK Menteri Perhubungan No: Pm 10/Pw 301/ Phb 77 (Sri Perwani, 1993: 2), Hotel adalah suatu bentuk akomodasi yang dikelola secara komersil, yang disediakan bagi setiap orang untuk memperoleh pelayanan, penginapan berikut makan dan minum.

Berdasarkan penjabaran tersebut, maka pengertian hotel adalah salah satu jenis akomodasi yang dikelola secara komersil, yang menyediakan pelayanan penginapan, makan, minum, kepada para tamu yang tinggal untuk sementara waktu di tempat tersebut. Dalam penelitian ini hotel yang dimaksud adalah Natya Hotel yang berlokasi di Tanah Lot, Tabanan, Bali.

\subsection{LANDASAN TEORI}

SOP di suatu usaha perhotelan atau organisasi, haruslah sesuai dengan budaya dan sistem hotel itu sendiri. Karena inti dari pembuatan SOP ini adalah untuk memudahkan dan menjelaskan proses suatu kegiatan oleh semua pihak. Menurut Stup (2001), ada beberapa bentuk dan kriteria dalam pembuatan SOP:

1) Simple Steps Prosedur, merupakan bentuk SOP yang singkat dan tidak membutuhkan banyak keputusan yang ditulis. SOP ini biasanya digunakan oleh perusahaan yang memiliki pekerja yang tidak terlalu banyak.

2) Hierarchical Steps, merupakan beentuk SOP yang cukup panjang lebih dari 10 langkah, tetapi tidak terlalu banyak keputusan.

3) Graphic Fomrat, merupakan bentuk SOP yang sama seperti Hierarchical Steps yaitu cukup panjang lebih dari 10 langkah tetapi tidak terlalu banyak keputusan. Perbedaannya yaitu dalam 
penyampaiannya. Graphic Format berisikan suatu grafik, gambar, maupun diagram untuk mengilustrasikan tujuan dari suatu prosedur.

4) Flowchart Prosedur, yaitu SOP yang memiliki banyak keputusan. Flowchart merupakan SOP yang berbentuk grafik sederhana yang menjelaskan langkah-langkah dalam membuat keputusan. Hal yang harus diperhatikan dalam pembuatan Flowchart ini yaitu pemakaian simbol-simbol dalam penjelasanya, karena memiliki arti dan makna yang berbeda.

SOP harus ditulis dengan cukup detil sedemikian rupa sehingga seseorang dengan pemahaman yang sangat basic dari suatu bidang, dapat dengan sukses atau mudah melakukan aktivitas atau melakukan prosedur atau langkah ketika tanpa supervisi.

\section{METODE PENELITIAN}

Penelitian ini merupakan penelitian yang menggunakan pendekatan kualitatif. Penelitian kualitatif adalah suatu penelitian yang menghasilkan data deskriptif berupa kata-kata tertulis atau lisan dari orang-orang dan perilaku yang dapat diamati. Creswell (2010: 4) menyatakan bahwa penelitian kualitatif adalah suatu proses penelitian ilmiah untuk memahami masalah-masalah manusia dalam konteks sosial dengan menyajikan gambaran menyeluruh dan kompleks, melaporkan pandangan terperinci, serta dilakukan dalam setting yang alamiah dan tidak ada intervensi dari peneliti. Penelitian ini bertujuan untuk mengetahui dan memperoleh gambaran mengenai pelaksanaan SOP Room service Natya Hotel, Tanah Lot. Dengan pendekatan kualitatif peneliti dapat mengeksplorasi Natya Hotel, situasi, kondisi, dan permasalahan yang berkaitan dengan pelaksanaan SOP Room service Natya Hotel. 
Teknik pengumpulan data adalah hal yang paling penting dlaam suatu penelitian, karena tujuan utama dari penelitian adalah mendapatkan data. Tanpa mengetahui teknik pengumpulan data, maka peneliti tidak akan mendapatkan data yang dibutuhkan. Teknik pengumpulan data yang digunakan dalam penelitian yaitu sebagai berikut:

1. Observasi

Sugiono (2010) menyatakan bahwa observasi adalah dasar semua ilmu pengetahuan. Para ilmuan hanya bisa bekerja melalui data, yaitu fakta melalui dunia kenyataan yang diperoleh melalui observasi. Observasi yang dilakukan adalah dengan melakukan pengamatan secara langsung tentang hal-hal yang bersangkutan dengan variabel penelitian untuk memperoleh data yang diperlukan.

2. Wawancara

Menurut Sugiono (2010) wawancara adalah pertemuan dua orang untuk bertukar informasi dan ide melalui Tanya jawab sehingga dapat dikonstruksikan makna dalam suatu topik tertentu dan dengan wawancara peneliti akan mengetahui hal-hal yang lebih mendalam tentang partisipan dalam menginterpretasikan situasi dan penomena yang terjadi yang tidak mungkin bisa ditemukan melalui observasi.

3. Studi kepustakaan

Menurut Sugiono (2010) menyatakan bahwa studi pustaka merupakan langkah awal dalam metode pengumpulan data. Studi pustaka merupakan metode pengumpulan data yang diarahkan kepada pencarian data dan informasi melalui dokumen- dokumen, baik dokumen tertulis, foto- foto, gambar, maupun dokumen elektronik yang dapat mendukung dalam proses penulisan. 


\section{GAMBARAN NATYA HOTEL, TANAH LOT}

Natya Hotel Tanah Lot terletak di Tanah Lot, menawarkan akses langsung ke Pura Tanah Lot yang hanya berjarak 100 meter. Terletak di sebelah Nirwana Bali Golf Course, Natya Hotel Tanah Lot berjarak 40 menit berkendara ke tempat-tempat hiburan di Seminyak dan dari Bandara Internasional Ngurah Rai dapat dijangkau dalam 1,5 jam berkendara.

Hotel ini menyediakan restoran, kolam renang outdoor, dan kamarkamar ber-AC yang dilengkapi TV kabel layar datar. Akses Wi-Fi dan tempat parkir juga tersedia gratis. Menampilkan teras pribadi yang menghadap ke kolam renang dan taman, kamar-kamar Natya Hotel Tanah Lot berada di taman yang asri. Kamar-kamarnya dihiasi interior modern dan pencahayaan yang hangat. Tersedia minibar, brankas, serta kamar mandi pribadi dengan fasilitas bathtub dan shower.

Di Natya Hotel pengunjung dapat berkuda, bersepeda, atau menikmati pijat tubuh yang menenangkan. Natya Hotel Tanah Lot juga menyediakan penyewaan mobil dan layanan antar-jemput bandara. Pengaturan perjalanan dapat dilakukan di meja layanan wisata. Restoran hotel menyajikan masakan khas Indonesia dan Barat.
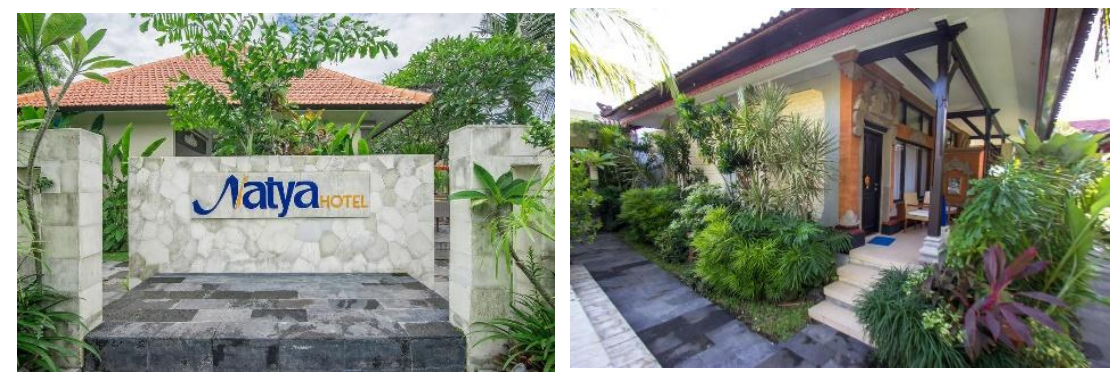

Gambar 1 Natya Hotel, Tanah Lot

Sumber: https://www.booking.com/hotel/id/natya-tanah-lot.id.html 


\section{PEMBAHASAN}

Pembahasan akan memaparkan jawaban dari masalah yang ada dalam penulisan ini, untuk lebih jelasnya dapat dilihat di bawah ini

\subsection{SOP ROOM SERVICE NATYA HOTEL}

Berdasarkan hasil observasi dan wawancara, berikut SOP Natya Hotel dalam melayani tamu melalui room service nya:

1. Cara Menangani Pesanan Tamu di kamar (room service) Natya Hotel, Tanah Lot :

a. Pintu kamar tamu pelan-pelan tidak terlalu keras asal tamunya mendengar dan dengan sopan ucapkanlah selamat pagi, siang ataupun sore

b. Jangan masuk ke kamar sebelum diizinkan oleh tamu

c. Periksalah bahwa segala sesuatunya sudah benar dan telah tersusun rapi diatas meja dan lengkapilah dengan kursi bila diperlukan

d. Janganlah cepat-cepat meninggalkan tamu apabila belum yakin benar bahwa sesuatunya telah beres.

2. Pelayanan dalam bidang kuliner termasuk dalam perhatian Natya Hotel, Tanah Lot. Oleh karena itu, peneliti juga melakukan observasi dan pencatatan terkait dengan penataan alat makan oleh room service man. Tugas room serviceyang beraneka ragam termasuk dengan melakukan penataan. Adapun SOP Penataan (set up) alat makan pelayanan di room service di Natya Hotel Bali:

a. Bersihkan dan siapkan piring, sendok, garpu, gelas terlebih dahulu

b. Ambil makanan yang telah jadi dari kitchen area

c. Siapkan trolley terlebih dahulu

d. Angkat makanan secara perlahan dan letakkan diatas trolley

e. Antarkan ke kamar tamu. 
3. Setelah penjabaran mengenai penataan. Selanjutnya adalah deskripsi prosedur pengangkatan peralatan kotor dari kamar tamu. SOP mengangkat peralatan kotor dari kamar tamu di Natya Hotel Bali:

a. Tunggu 1 jam setelah pengiriman dan tamu akan memberitahukan bagian room service agar piring kotor segera diangkat.

b. Gunakan format pencatatan peralatan yang digunakan baik untuk pengiriman maupun pengembalian

c. Masuk ke kamar tamu bila tamu sudah mempersilahkan

d. Minta bantuan room boy atau room maid untuk membukakan pintu kamar

e. Angkat semua piring kotor dan susun diatas baki

f. Jumlah baki dan peralatan yang ada harus sesuai dengan pada waktu pengiriman.

g. Laporkan bila ada kehilangan

Dalam menjalankan tugasnya seorang room serviceman harus memenuhi syarat-syarat sebagai berikut:

1. Room serviceman harus menguasai menu room service. Selain itu juga harus mengetahui tentang hotel beserta segala fasilitas yang ada dihotel.

2. Room serviceman harus selalu membawa buku kecil untuk mencatat pesanan tamu.

3. Room serviceman harus mengerti bagaimana sopan santun.

4. Room serviceman mengerti teknik menjual dengan baik.

5. Room serviceman harus dapat bersikap layaknya tuan rumah yang baik, yang harus terus berusaha menyuguhkan hal - hal yang membuat tamu merasa senang.

6. Untuk mencegah salah pengertian dari kata asing atau yang sulit sebaiknya Room serviceman harus mengetahui cara mengeja alphabet 
(spelling).

7. Room serviceman sebaiknya mengerti kapan menggunakan magic word,seperti: Thank you, I'm sorry, Pardon me, May I help you dan sebagainya.

\subsection{KENDALA PELAKSANAAN SOP ROOM SERVICE NATYA}

\section{HOTEL, TANAH LOT}

Berdasarkan hasil observasi dan wawancara, kendala yang dihadapi room service man Natya Hotel, Tanah Lot dalam melaksanakan SOP Room service Natya Hotel, Tanah Lot yaitu sebagai berikut:

1) Sedikitnya staff yang bertugas menyebabkan room service man Natya Hotel, Tanah Lot tidak melakukan SOP yang sudah ditentukan. Solusi untuk menangani masalah seperti ini yaitu dibutuhkan sistem kerja yang efisien dengan melakukan pembagian jadwal kerja sesuai kemampuan staff yang ada. Perlu juga dibuat pembagian tempat kerja sesuai area masing-masing atau membuat kelompok kerja dengan satu orang penanggung jawab serta melakukan perekrutan karyawan baru agar tidak ada lagi kekurangan staff pada saat operasional. Pembagian tugas juga cukup membantu room service man Natya Hotel, Tanah Lot, sehingga tidak terlalu hectic untuk melakukan tugasnya dan jika memiliki kendala langsung diserahkan kepada penanggung jawab. Hal seperti ini dilakukan apabila jumlah room service man Natya Hotel, Tanah Lot yang bertugas sedikit dan tamu yang yang menggunakan pelayanan room servicebanyak

2) Kurangnya koordinasi dan komunikasi antara senior dan bawahan. Kurangnya koordinasi dan komunikasi terkadang menyebabkan tidak terselesaikannya suatu perkerjaan. Solusi nya dengan mengadakan briefing secara intensif dari senior kepada junior sebelum dan sesudah pergantian shift. Melalui briefing diharapkan mampu 
memberikan pembekalan informasi yang baik dan terkini sehingga hal-hal yang perlu ditinjaklanjuti akan terlaksana. Juga, agar rasa kerjasama, persaudaraan, dan keakraban di antara senior dan junior dapat dijembatani tanpa membedakan status. Isi dari briefing ini dapat berupa motivasi dalam kerja, hal-hal yang perlu ditindaklanjut serta pengetahuan tentang menu ataupun produk. Dengan dilakukannya strategi ini diharapkan mampu mengurangi kesalah pahaman, ketidaktahuan suatu menu atau produk, meningkatkan kualitas pelayanan dan mempererat tali persaudaraan satu sama lain.

3) Lebih dari setengah jumlah room service man Natya Hotel, Tanah Lot hanya bisa mengerti apa yang diucapkan dalam bahasa Inggris akan tetapi pada saat melakukan percakapan masih sering tersendat dan kurang terorganisir kalimat-kalimatnya. Hal ini merupakan masalah yang serius karena dapat menghambat proses komunikasi saat menawarkan produk hotel dan menimbulkan dampak negatif kepada pihak hotel karena cara berkomunikasi yang kurang baik ini dapat membuat image hotel menjadi buruk dan kepercayaan yang memudar dari pelanggan, terutama pelanggan asing.

\subsection{UPAYA PENINGKATAN PROFESIONALISME ROOM SERVICE} MAN NATYA HOTEL, TANAH LOT

SOP room servicedi Natya Hotel, Tabanan merupakan dasar untuk meningkatkan profesionalisme, karena SOP sangat membantu membiasakan para Room service man untuk disiplin mengemban amanah dalam program-program kerja yang berdampak mampu menciptakan ideide kreatif bagi hotel. Dengan adanya penerapan SOP yang baik oleh room service di Natya Hotel, dapat menciptakan Room service man yang memiliki keterampilan tinggi dalam bidang pelayanan serta mahir dalam menggunakan peralatan untuk melayani tamu sehingga dapat bekerja 
secara professional. Room service man juga diharapkan memiliki ilmu dan pengalaman serta kecerdasan dalam menganalisis suatu masalah dan peka didalam membaca situasi, cepat, tepat serta cermat dalam mengambil keputusan ssecara profesional.

Pelayanan Room service man kepada tamu harus senantiasa meningkat agar tamu yang berkunjung ke hotel merasa puas dan kembali lagi ke hotel. Berikut adalah upaya yang dilakukan Natya Hotel, Tanah Lot dalam meningkatkan profesionalisme Room service man dalam meningkatkan pelayanan:

1) Melalui pelatihan yang diadakan rutin setiap satu bulan sekali. Di dalam pelatihan tersebut materi yang sering disampaikan adalah Mental dasar, Penampilan dan perilaku Room service man, cara melayani atau menjual produk dan menyajikan pesanan kepada tamu. Di dalam pelatihan biasanya dilakukan pengenalan menu baru dan cara memberikan pelayanan sesuai dengan standar hotel. Penguasaan product knowledge sangat penting agar mampu menjelaskan kepada tamu tentang menu yang ada di restoran. Room service man harus senantiasa belajar tentang produk yang dijual.

2) Pemberian penghargaan berupa piagam dan penambahan bonus terhadap karyawan termasuk Room service man terbaik setiap tiga bulan serta satu tahun sekali guna mendongkrak kinerja karyawan untuk bekerja sebaik mungkin.

3) Melakukan perbandingan Room service man dengan hotel lain yang lebih baik, sehingga para Room service man mengetahui dan terbiasa bagaimana melayani tamu dengan baik dan sesuai standar hotel.

4) Mengadakan outbond untuk karyawan termasuk Room service man, selain untuk hiburan juga untuk melatih kerjasama

5) Melakukan sistem pengawasan kerja yang baik, F\&B Service Supervisor senantiasa melakukan pengawasan secara langsung di 
lapangan pada saat operasional. Hal ini dimaksudkan untuk melihat secara langsung kendala-kendala yang terjadi dan dapat mengganggu jalannya operasional, seperti meneliti peralatan restaurant baik dari segi kualitas dan kuantitas. F\&B Service Supervisor juga melakukan pendekatan-pendekatan secara persuasif dalam mengatasi berbagai masalah yang dialami oleh Room service man yang dapat mengganggu produktifitas kerja. Pembinaan secara persuasif ini juga dilakukan dengan tujuan agar tercapainya keharmonisan hubungan kerja antara karyawan dengan atasan.

\section{PENUTUP}

Room service di Natya Hotel telah memiliki SOP yang telah ditetapkan. SOP ini ditentukan oleh manajemen Hotel tersebut dan diimplementasikan oleh karyawan room service yang terdaftar sebagai pekerja dalam hotel. SOP yang dijalankan di Natya Hotel pada departement room service yaitu menerima oderan dari telepon, membuat captain order, mempersiapkan peralatan, pesanan diantar ke kamar tamu. Prosedur menangani pesanan tamu (order) ke room service, penataan (set up) alat makan pelayanan di room service, prosedur mengangkat peralatan kotor dari kamar tamu sudah sesuai dengan SOP.

Dalam penelitian ini penulis menemukan beberapa kendala dalam penerapan SOP room service Natya Hotel, Tanah Lot. Adapun Kendala yang dihadapi adalah kurangnya staff, kurangnya koordinasi dan komunikasi anatar senior dan bawahan, kurangnya kemampuan berkomunikasi dengan tamu asing dalam bahasa inggris. Staff room service tidak cakap berkomunikasi dalam bahasa Inggris karena kurangnya pengetahuan, materi yang diberikan kurang menekankan pada penggunaan komunikasi bahasa Inggris praktis terapan dan kurang didisiplinkannya penggunaan bahasa Inggris. 
Sejauh ini upaya yang telah dilakukan oleh Natya Hotel, Tanah Lot adalah dengan 1) melaksanakan pelatihan Mental dasar, Penampilan dan perilaku Room service man, cara melayani atau menjual produk dan menyajikan pesanan kepada tamu termasuk juga pelatihan penguasaan product knowledge; 2) Pemberian penghargaan guna mendongkrak kinerja; 3) Melakukan perbandingan Room service man dengan hotel lain yang lebih baik, 4) Mengadakan outbond untuk melatih kerjasama; 5) Melakukan sistem pengawasan kerja yang baik. Dengan adanya upaya upaya peningkatan profesionalisme Room service man tersebut diharapkan dapat meningkatkan pelayanan dan kenyamanan terhadap tamu di Natya Hotel, Tanah Lot.

Berdasarkan hasil pengamatan yang peneliti lakukan bahwa pihak HRD kurang menekankan kemampuan berbahasa inggris pada saat perekrutan karyawan baru. Hal ini terbukti dari hasil kinerja para Room service man yang kurang memuaskan pada saat melayani tamu apalagi tamu asing. Adapun pemecahan masalah yang dapat ditawarkan peneliti adalah

1) Melakukan penyeleksian pegawai dengan lebih selektif dan jujur terhadap kapasitas calon karyawan.

2) Meningkatkan kemampuan staff untuk berkomunikasi dalam bahasa inggris dengan memberikan kursus bahasa inggris gratis dan seminar komunikasi praktis terapan

3) Menciptakan atmosfer yang akrab dengan selalu berkomunikasi dalam bahasa Inggris dalam setiap briefing.

4) Mendisiplinkan staff untuk berkomunikasi dalam bahasa inggris secara rutin setiap hari.

5) Memberi motivasi pada staff agar mempunyai semangat untuk berubah dan mau dibina

6) Melakukan komunikasi interpersonal dengan staff 
7) Diperlukan juga pelatihan yang dilakukan rutin setiap satu bulan sekali, dimana pelatihan tersebut hal pokok yang sering disampaikan adalah materi mengenai cara memberikan pelayanan yang baik kepada tamu dan cara memberikan pelayanan sesuai dengan SOP yang telah ditetapkan di Natya Hotel, Tanah Lot.

Adanya kendala yang dihadapi Room service man dalam menjalankan SOP merupakan sebuah tantangan yang harus di selesaikan dengan bijaksana dan memiliki solusi yang tepat. Kendala yang dihadapi Room service man dapat dijadikan sebuah motivasi untuk maju dan lebih baik lagi. Dari penelitian yang telah dilakukkan peneliti disimpulkan bahwa pelayanan Room service man berpengaruh terhadap peningkatan kualitas pelayanan tamu khususnya di Hotel Natya Hotel, Tanah Lot

Penulis menyarankan agar dalam penelitian selanjutnya melaukan observasi yang lebih mendalam, terlebih berinteraksi lebih banyak dengan tamu hotel, sehingga dapat menemukan lebih dalam mengenai prosedur pesanan tamu (order) ke room service.

\section{DAFTAR PUSTAKA}

Arief, Rahman, Abdul. 2005. Pengantar Ilmu Perhotelan dan Restoran. Yogyakarta: Graha Ilmu.

Bagyono. 2007. Pariwisata dan Perhotelan. Bali: Alfabeta cv.

Bagyono. 2012.Pariwisata dan Perhotelan. Bali: Alfabeta cv.

Bartono, P.H., SE dan Ruffino E.M., SE, 2007. Hotel Communication Management, Yogyakarta: ANDI Dumond, Karen E, 1992. The Restaurant Training Program. Canada. Jhon Wiley and Son Inc New International Student's Edition. Oxford Advance Learner"s Dictionary.

Derianto dan Kristiutami. 2015. Standar Operasional ProsedurRoom service Amaroossa Hotel Bandung. Jurnal Pariwisata, Vol.II No.1 April 205

Marsum. 2005. Restoran dan Segala Permasalahannya. Yogyakarta: ANDI.

Nazir, Mohammad. 2011. Metode Penelitian. Jakarta: Ghalia Indonesia. Suarthana. 2006. Perhotelan Edisi Kantor Depan. Kuta Utara: Mapindo. 
Pratiwi. 2016. Penerapan Prosedur Operasional Standar Make Up Room Oleh Roomboy di Hotel Daima Padang. Fakultas Pariwisata Dan Pehotelan Universitas Negeri Padang

Sugiono. 2010. Metode Penelitian Kuantitatif, Kualitatif \& RND. Bali: Alfabeta.

Sulastiyono, Agus. 2007. Teknik dan Prosedur Divisi kamar pada bidang Hotel. Bali: Alfabeta

Sujatno, Bambang. 2008. Hotel Courtesy. Yogyakarta: Cv. Andi Offset. Sulastiyono, Agus. 2007. Teknik dan Prosedur Divisi kamar pada bidang Hotel. Bali: Alfabeta cv.

Wiwoho, Adjuno. 2008. Pengetahuan Tata Hidang. Yogyakarta: PT Gelora Aksara Pratama.

Yuanti dan Luckyrainita. 2017. Layanan Makanan dan Minuman di Hotel Amaris Diponegoro Yogyakarta.Jurnal Pariwisata Terapan, No. 1, Vol. 1.

\section{PROFIL PENULIS}

Rimalinda Lukitasari, S.S., M.Par lahir di Surabaya, Jawa Timur, 16 Desember 1982. Ia menyelesaikan pendidikan sarjana sastra di Universitas Udayana pada tahun 2010. Melihat potensi dunia pariwisata Indonesia yang sangat baik, maka Rimalinda melanjutkan studi magister di Kajian Pariwisata, Program Pascasarjana Universitas Udayana, dan lulus pada tahun 2016. Dalam dunia kepariwisataan, Rimalinda adalah seorang praktisi dalam bidang pengelolaan peristiwa (Event Management). Salah satu kegiatan yang ikut dikelola adalah Berawa Beach Arts Festival di Tibubebeng, Badung, Bali pada Februari 2018. Ia juga tergabung dalam sebuah perusahaan media social management yang menangani usaha-usaha di bidang pariwisata, sebagai seorang content writer. Selain berkecimpung dalam industri pariwisata secara langsung, Rimalinda juga merupakan seorang wirausahawan di bidang desain dan produksi aksesoris serta garmen yang secara khusus bertanggungjawab dalam pengelolaan pemasaran dan merchandising. Saat ini, ia bergabung sebagai seorang dosen di Politeknik Internasional Bali, dengan pengalaman mengajar di bidang manajemen risiko, komunikasi, kewarganegaraan, serta juga mengajar manajemen destinasi bagi mahasiswa internasional. Selain itu, ia juga seorang penulis cerita fiksi dan juga seorang microblogger yang aktif mempromosikan kuliner nusantara. 